\title{
Seroprevalence of Human Brucellosis Among High Risk and Normal Individuals of Sylhet District in Bangladesh
}

\author{
Akhtar $\mathrm{J}^{1 *}$, Chowdhury $\mathrm{OA}^{2}$, Das $\mathrm{P}^{3}$, Sinha $\mathrm{SP}^{4}$ \\ ${ }^{I}$ Department of Microbiology, Sir Salimullah Medical College, Dhaka, Bangladesh; ${ }^{2}$ Department of \\ Microbiology, Parkview Medical College, Sylhet, Bangladesh; ${ }^{3}$ Department of Microbiology MAG \\ Osmani Medical College, Sylhet, Bangladesh; ${ }^{4}$ Department of Virology Osmani Medical College, \\ Sylhet, Bangladesh.
}

\begin{abstract}
Background: Brucellosis is an important re-emerging zoonosis which remains an uncontrolled public health problem worldwide because of serious diminution of manpower, animals and essential foodstuffs. Transmission to human can occurs through contact with infected animals or animal products. It is a poorly recognised health problem in this country though there is persistence of large reservoirs of the organism among livestock such as sheep, goat and cows creating fertile field for unabated transmission. But data on it's transmission potential and prevalence in this country specially in Sylhet region remained scarce. In the absence of supportive epidemiological information physicians on most of the cases have to depend on their clinical judgement to suggest relevant tests.
\end{abstract}

Objective: The study was conducted to compare the sero-prevalence of human brucellosis among high risk and normal individuals.

Methods: This cross-sectional, comparative study was conducted amongst a total of randomly selected 90 participants including 65 high risk individuals during the period of July 2016-June 2017. Brucella IgM and IgG antibody in the serum were determine by Enzyme Linked Immunosorbent Assay (ELISA) technique.

Results: Among the 65 participants of the high risk group, Brucella IgM and IgG seropositivity were found in $6(9.2 \%)$ and $32(49.2 \%)$ cases respectively. On the other hand, no IgM seropositivity, but 10 $(40.0 \%) \mathrm{IgG}$ seropositivity cases were found in normal group. No significant difference $(p>0.05)$ was found between the groups. Considering occupations, the highest $11(61.1 \%)$ Brucella IgG seropositivity was found among the 18 dairy farm workers $(p>0.05)$. Participants with $0-5$ years duration of job had highest seropositivity 7 (70\%) among high risk group and 3 (50\%) among normal group. No significant association was identified between seropositivity and duration of occupation, education $(p>0.05)$.

Conclusion: Based on the study findings, it may be concluded that the extent of human brucellosis should not be ignored, and measures like awareness building, vaccination, transboundary screening needed to prevent and control the disease in animals and limit human transmission.

Keywords: Brucellosis, Brucella IgM, Brucella IgG, Seroprevalence

\section{Introduction}

Brucellosis is a highly contagious and important zoonotic disease, caused by gram negative coccobacillus belonging to genus Brucella. This is a disease of domestic and wild animals. Infections in humans result from direct or indirect contact with animal sources. The disease is also called 'Malta fever', 'Mediterranean fever' and 'Undulant fever' are probably the best known. ${ }^{1}$ The main domestic animals that are affected are cattle, sheep, goats and pigs. ${ }^{2}$ The principal manifestations of animal brucellosis are reproductive failure resulting in abortion, still

*Correspondence: Dr Jasmin Akhtar, Assistant Professor, Department of Microbiology, Sir Salimullah Medical College, Dhaka:

e-mail:dr.shimu111@gmail.com; ORCID: 0000-0002-5933-2259 birth, retention of placenta and reduce milk yield. ${ }^{3}$ Brucellosis in human being is usually manifests as an acute or subacute febrile illness, which may persist, and progress to a chronically in capacitating disease. $^{4}$ The most common presenting symptom is fever (78\%) accompanied by arthralgia (65\%), myalgia ( $47 \%$ ) and back pain $(45 \%) .{ }^{5}$ Severe complications includes with one case of endocarditis and four neurological cases per 100 patients and one in 10 men suffers from epididymo-orchitis as reported by Dean in 2012. Brucellosis is an ancient disease. Early indication of brucellosis date back to the Crimean War (1853-1856) which was discovered by Dr. David Bruce in $1887 .{ }^{1}$ Brucellosis is acquired by direct contact with vaginal discharge, urine, faeces and 
blood of infected animals through cutaneous, respiratory and conjunctival routes. The indirect transmission to humans takes place through the consumption of undercooked meat, unpasteurized milk or milk products containing viable organisms. ${ }^{6}$ The occupational source of exposure predisposes the farmers, shepherds, butchers, laboratory workers, veterinarians and slaughterhouse workers to a greater risk of contracting the disease through inhalation of contaminated aerosols, contact with conjunctival mucosa, or entry of the bacteria through cuts and abrasions in the skin. ${ }^{7}$

Brucellosis has a great public health significance because of serious diminution of man power, animals and essential foodstuffs. ${ }^{8}$ More than 500,000 new cases of human brucellosis reported annually. ${ }^{9}$ The disease is endemic in many developing countries of Latin America, Africa and Asia including Bangladesh. It is recognized health problem in our country due to the persistence of large reservoirs of the organism among livestock. ${ }^{10}$ In Bangladesh, about $80 \%$ of total population live in villages and the rural income relies largely on livestock breeding and dairy products and the people has every day close contact with the livestock. Human brucellosis is caused by exposure to livestock and livestock products. ${ }^{11}$ consequently the disease is recognized as an occupational disease in Shepherds, Butcher, Abattoir, Veterinarians and Laboratory workers. ${ }^{8}$ Several studies indicate that human brucellosis is a fairly common disease in India. Mathur reported $8.5 \%$ sero-prevalence of brucellosis among dairy personnel in contact with infected animals. ${ }^{12}$ In Bangladesh, sporadic reports of human \& animal brucellosis were recorded. The true incidence of human brucellosis in our country is not known. ${ }^{10}$ The sero-prevalence study of brucellosis in cattle and human in contact was conducted by Nahar and Ahmed in 2009. They reported brucellosis $4.5 \%$ in cattle and $6 \%$ in humans having close contact with cattle. ${ }^{13}$ In one study, conducted by Rahman et al. in 2014, the sero-prevalence of brucellosis in a high risk group of individuals, $2.6 \%$ in farmers, $18.6 \%$ in milker, $2.5 \%$ in butcher, and $5.3 \%$ in veterinary practitioners. ${ }^{14}$ Muhammad et al. analyzed 210 human sera of people at risk in the Mymensingh district using a variety of Brucella serological tests. Among occupational groups seropositivity were found in
$11.1 \%$ of veterinary personel, $6.5 \%$ of dairy workers and $4.7 \%$ of animal farmers. ${ }^{20}$ The result of all sero-prevalence studies traced, indicated that brucellosis is an occupational health hazard in Bangladesh. The importance of brucellosis is not known precisely, but it can have a considerable impact on human and animal health. Brucella species usually cause abortion in their natural hosts, resulting in huge economic losses and severe human disease. ${ }^{15}$ For these reasons it is likely that, brucellosis remain a high risk zoonotic disease in our country, the extent which still remained poorly explored. The study data so acquired will highlight the prevailing situation in high risk population in a divisional city and may be utilized to develop a comprehensive strategy to prevent the spread brucellosis in our country. So this study has been designed to evaluate the seroprevalence of human brucellosis between high risk individuals and normal individuals.

\section{Materials and Methods}

In this cross-sectional comparative study the rate of Brucella species Seropositivity was investigated in the Department of microbiology, Sylhet MAG Osmani Medical College, Sylhet during July 2016 to June 2017. The study population consisted of 2 groups: High risk individuals (group 1, $\mathrm{n}=65$ ) and normal group (group 2, $\mathrm{n}=25$ ), were randomly selected from the Sylhet city. High risk group includes meat-shop workers, slaughterhouse workers, veterinarians, dairy farm workers and normal group means apparently healthy individuals having no history of close contact with cattle, raw meat and no history of taking unpasteurized milk and milk product. People who are not willing to participate and people who are taking immunosuppressive drug or suffering from immunodeficiency disease were excluded from this study. Sample size was calculated considering the prevalence of human brucellosis in Dhaka district $24 \%$ with $5 \%$ significance level and 10\% marginal error. Sample size was calculated by using the $^{\text {ung }}$ Guilford and Frucher's formula, $n=\frac{Z^{2} \times p q}{d^{2}}$. The calculated sample size was 70 . For better evaluation of sero-prevalence sample size taken was 90 . Sampling technique was simple random sampling. After selection of study population all members were given individual identification numbers. Participants of sample population were selected through lottery by hand. Data were collected in a 
preformed data collection sheet. All the participants gave informed written consent to participate in this study. The participants were asked to complete a questionnaire consisted of question about their demographic data (Age, Education, Occupation, Duration of occupation). Ethical clearance was obtained from the Ethical Review Committee of Sylhet MAG Osmani Medical College beforehand. All the ethical committee guidelines were followed during the conduction of the study. With all aseptic precaution $3 \mathrm{ml}$ of venous blood were collected from each participant's by venepuncture. Samples were taken into sterile test tubes and allowed to clot at room temperature for about 30 minutes. Serum was separated by centrifuging at $2000 \mathrm{rpm}$ for 10 minutes and transferred to an eppendorf tube with proper labelling. Serum was stored at $-20^{\circ} \mathrm{C}$ until further analysis. The sera were analyzed using Enzyme Linked Immunosorbent Assay technique for Anti-Brucella IgM and IgG (CALBIOTECH, USA). Manufacturer of the reagent: CALBIOTECH A life science company, CA 92020 U.S.A. Catalog \# BA053M, Lot no: BAM5028, Kit name: BrucellaIgM. Catalog \# BA052G, Lot no: BAG5124, Kit name: BrucellaIgG. These kits were used for the qualitative determination of AntiBrucella IgM and IgG. Data were processed and analyzed with the help of SPSS (Statistical Package for Social Sciences) Version 21.0. Different Qualitative and Quantitative data were collected and analyzed in this study. Quantitative continuous data were recorded into categorical values for further analysis. Association between variables has been analyzed using chi-square analysis and presented along with frequency and percentages. For proportional comparison for target variables, proportional z-test has been used and presented along with frequency and percentage. Comparison was seen by proportional z-test. A probability value $(p) \leq 0.05$ was considered statistically significant.

\section{Results}

A total of 90 individuals participated in this study. All the participants were male with age ranging from $18-60$ years. The largest number (35.4\%) was in 1830 years. Majority of the respondents had primary education $54(83.1 \%)$. In high risk group $(\mathrm{n}=65)$ slaughter house workers $16(25.0 \%)$, meat shop workers 19 (29.0\%), dairy farm workers 18 (28.0\%) and vaterinarians 12 (18.0\%).

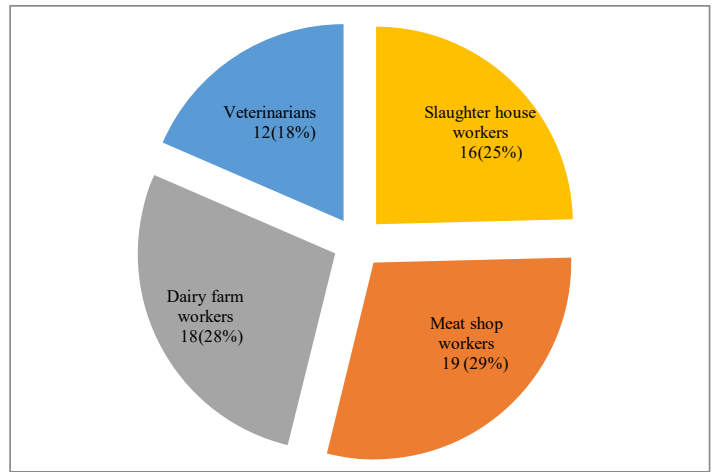

Figure 1: Pie chart showing the distribution of the participants in the high risk group.
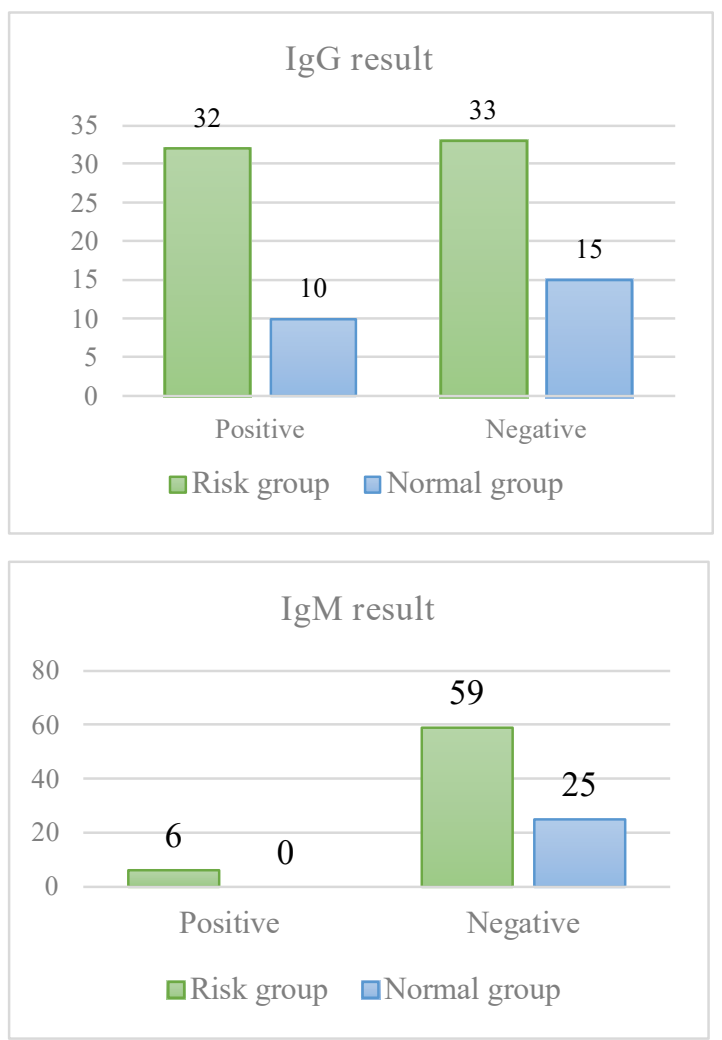

Figure 2: Immune status of participants

The analysis of their blood samples using ELISA technique showed that, in high risk group Brucella IgM seropositivity was seen $6(9.2 \%)$ and Brucella IgG seropositivity was found 32(49.2\%). In normal group no IgM seropositive participants were found and $10(40.0 \%)$ Brucella $\mathrm{IgG}$ seropositive participants were found.

Between high risk group and normal group the maximum Brucella IgG seropositivity had $14(60.9 \%)$ and $3(60 \%)$ respectively in the age group of $18-30$ years. There was no statistically significant difference between different age groups and seropositivity $(p>0.05)$ (table I). 
Table I: Demographic characteristics

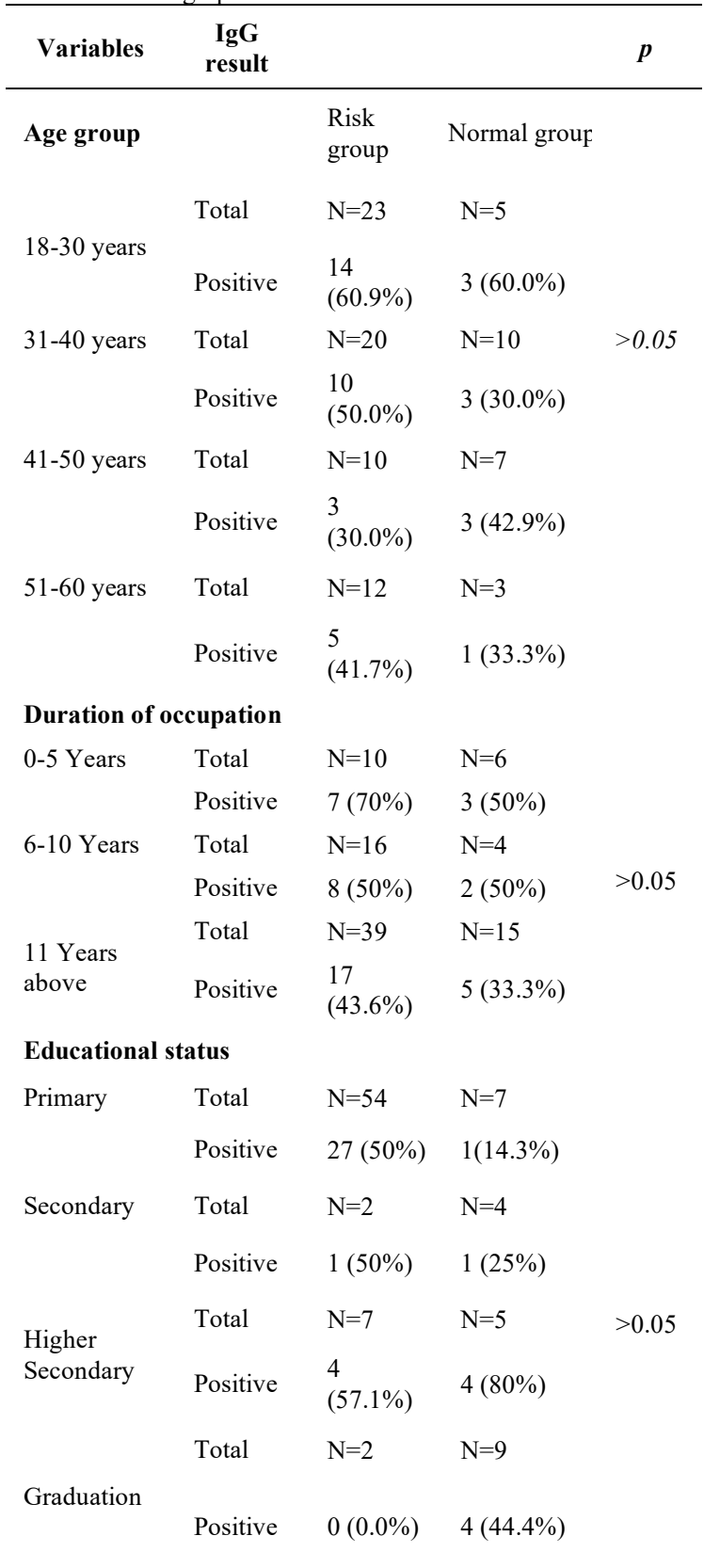

Duration of current occupation of the participants had divided into three groups. Participants (both high risk and normal group) with 0-5 years duration of job had a highest seropositivity 7 $(70.0 \%)$ and $3(50.0 \%)$ respectively. The statistical comparison between high risk group and normal group regarding Brucella seropositivity with duration of occupation $0-5$ years produced insignificant result $(p>0.05)$. The maximum $\operatorname{IgG}$ seropositivity was found in participants with education up to higher secondary level.
Table II: Seropositivity by occupation of the participants in high risk group.

\begin{tabular}{lllll}
\hline $\begin{array}{l}\text { Occupation of } \\
\text { the participants } \\
\text { in high risk } \\
\text { group }\end{array}$ & $\begin{array}{l}\text { IgG } \\
\text { Positive } \\
(\mathbf{n = 3 2})\end{array}$ & $\begin{array}{l}\text { Negative } \\
(\mathbf{n = 3 3 )}\end{array}$ & $\begin{array}{c}\text { Chi- } \\
\text { square } \\
(\boldsymbol{p})\end{array}$ \\
\hline $\begin{array}{l}\text { Slaughterhouse } \\
\text { workers }\end{array}$ & $5(31.3 \%)$ & $11(68.8 \%)$ & 16 & \\
Abattoir workers & $10(52.6 \%)$ & $9(47.4 \%)$ & 19 & 3.177 \\
$\begin{array}{l}\text { Dairy farm } \\
\text { workers }\end{array}$ & $11(61.1 \%)$ & $7(38.9 \%)$ & 18 & $(0.365)$ \\
Veterinarians & $6(50.0 \%)$ & $6(50.0 \%)$ & 12 & \\
\hline
\end{tabular}

The highest seropositivity was found in dairy farm workers $11(61.1 \%)$ followed by meat shop workers $10(52.6 \%)$ and veterinarians $6(50.0 \%)$. The lowest seropositivity was seen in slaughterhouse workers 5(31.3\%). There was no significant association between Brucella IgG seropositivity and occupation of the participants in high risk group $(p>0.05)$ (table II).

Table III: Distribution of the participants by IgM and IgG status

\begin{tabular}{llrll}
\hline $\begin{array}{l}\text { IgM } \\
\text { result }\end{array}$ & $\begin{array}{l}\text { Risk } \\
\text { group }\end{array}$ & $\begin{array}{l}\text { Normal } \\
\text { group }\end{array}$ & Total & $\begin{array}{l}\text { Chi-square } \\
(\boldsymbol{p})\end{array}$ \\
\hline Total & $\mathrm{N}=65$ & $\mathrm{~N}=25$ & 90 & \\
Positive & $6(9.2 \%)$ & $0(0.0 \%)$ & $6(6.7 \%)$ & $2.473(0.116)$ \\
$\begin{array}{l}\text { IgG } \\
\text { result }\end{array}$ & & & & \\
Total & $\mathrm{N}=65$ & $\mathrm{~N}=25$ & 90 & \\
Positive & $32(49.2 \%)$ & $10(40.0 \%)$ & $42(46.7 \%)$ & $0.618(0.432)$
\end{tabular}

Brucella IgM and IgG seropositivity was found in $6(9.2 \%)$ and $32(49.2 \%)$ cases out of 65 cases in high risk group. In normal group Brucella IgM seronegativity was seen but there was $10(40 \%)$ IgG seropositivity was found. There was no significant association between high risk group and normal group $(p>0.05)$ (table III).

\section{Discussion}

The study was designed to see the sero-prevalence of human brucellosis in high risk individuals and normal individuals. In high risk group Brucella IgM and IgG antibody was found to be $6(9.2 \%)$ and $32(49.2 \%)$. In normal group no $\operatorname{IgM}$ seropositivity was recorded but there was 10 $(40.0 \%)$ IgG seropositivity was found. Initially IgM antibodies are produced followed within a few weeks by a switch to IgG synthesis. ${ }^{1} \operatorname{IgM}$ seropositivity indicating the insidious onset of the disease. Araj and Azzam in their study found IgM alone only in $2 \%$ cases of high risk group. ${ }^{16}$ So of this findings could be explained by this 
knowledge that $\operatorname{IgM}$ persistence was mostly recognized among persons in high-risk group exposure possibly due to repeated exposure to antigenic stimulus. In this study all participants in the control group had developed a previous infection evidenced by IgM sero-negativity and IgG seropositivity only. From this study it can be ascertained that among those in high risk group infection was mainly due to contact with animals and their products. In the control group, infection was mainly due to ingestion of unpasteurized dairy product as this group had no consistent history of contact with animals.

In this study regarding occupational group the maximum Brucella seropositivity was found in dairy farm workers $11(61.1 \%)$. Studies conducted by Rahman et al. from Bangladesh reported the higher seropositivity was also found among milker $(18.2 \%, \mathrm{n}=55) .{ }^{17}$ The dairy farm workers are professionally in close contact with animals during milking and assisting animals during parturition or handling of stillbirth (assisting uncomplicated births); hence these are the risk factors for developing the higher seropositivity among dairy farm workers. ${ }^{18}$ In present study other occupational group such as, in slaughtererhouse workers Brucella seropositivity was found $5(31.3 \%)$, abattoir workers 10 (52.6\%) and veterinarians $6(50.0 \%)$. In a separate study conducted by Mukhtar in Pakistan revealed that $(21.7 \%)$ seropositivity was found among slaughterhouse workers $(n=23){ }^{7}$ It was known that the slaughterhouse workers were directly exposed to viscera of infected animals making them vulnerable to infection through cuts and splashing of infected blood and other fluid in the conjunctiva. So, they were generally more prone to acquire infection as compared to other occupations. ${ }^{19}$ Chowdhury from Bangladesh examined thirty nine $(n=39)$ serum samples from meat-shop worker and showed high degree of seropositivity $29(74.0 \%)$ that was higher than this study. The meat-shop workers are very much vulnerable to occupational hazards like cuts on bare hands that function as a route of Brucella infection and thereby show high degree of seropositivity. ${ }^{10}$ Study conducted by Mahmud et al. reported the seropositivity was found $(11.1 \%$, $\mathrm{n}=9$ ) in veterinary personnel. ${ }^{20}$ This finding was lower than this study. A higher rate of prevalence in veterinarians was reported by Rana et al. $(27.7 \%)$ and Kumar $(28.6 \%) .{ }^{21}$ Veterinarians and para-veterinarians frequently handled diseased animals, assisted complicated birth and also practiced artificial insemination so are considered to be at high risk in getting infected by Brucella.
Duration of the job of these high risk professional was very important factor. The highest $(70.0 \%)$ of seropositivity ( $\operatorname{IgG}$ ) was found in the high risk group participants who were in $0-5$ years duration and $(50.0 \%)$ sero-positivity (IgG) seen in normal group of same duration. Similar finding had been reported by Aworth et al (79.6\%) seropositivity was found in high risk group having duration of occupation over 5 years. ${ }^{22}$ The IgG seropositivity was mostly occurred in high risk participants with higher secondary education (57.1\%) than that of high risk participants with primary education. It was to be found that participants having secondary and higher secondary level education were veterinarians by occupation and that is why they were constantly in close contact with the source of Brucella. Normal group participants with higher secondary education showed maximum percentage of IgG seropositivity $(80.0 \%)$. Probably these normal group people had history of frequent consumption of unhealthy dairy products and got infected in their lifetime. It had to depend on participant's memory regarding exposure to risk factors which might be misleading. However, these findings re-establish the fact that unpasteurised milk and dairy products could be unsafe to consume.

\section{Conclusion}

In conclusion, the findings of this study revealed that the sero-prevalence of human brucellosis among high risk group population was higher $(49.2 \%)$ than that of the control group (40\%) emphasizing the importance of contact infection. Although Brucellosis is a disease of major public health concern, reported human cases from some studies do not reflect the actual prevalence, as revealed by this study. Brucella IgM and IgG seropositivity had a high prevalence among dairy farm worker, owing to their close contact with animals. The nonexistence of vaccine against Brucellosis in human or the difficulty of accessing a safe and efficacious vaccine implies that contracting the zoonotic disease in animals will continue to dominate the Brucella transmission landscape in human brucellosis. The economic loss sustained from human and animal brucellosis in this country remains to be evaluated.

\section{Acknowledgments}

The authors gratefully acknowledge the laboratory support of the Department of Microbiology, Sylhet MAG Osmani Medical College, Sylhet for this study. Author are also thankful to all participants for their cooperation and participation. 
Conflict of interest: None

Funding: None

Submitted: $27^{\text {th }}$ October, 2019

Final revision received: $17^{\text {th }}$ March, 2020

Accepted: $19^{\text {th }}$ March, 2020

Published online: $1^{\text {st }}$ April, 2020

\section{References}

1. Murray PR and Corbel MJ. Brucella. In: Borellio SP, Murray PR, Fanke G, editors. Topley and Wilson Microbiology and Microbial Infections, 10th ed. PRESS; 2007: pp. 1719-51.

2. OIE).Chapter 2.3.1.Bovine Brucellosis.Manual of Diagnostic Tests and Vaccines for Terrestrial Animals.2000.

url: www.oie.int/esp/normes/mmanual/ooo52.htm.

3. Rahman MS, Uddin MJ, Park JH, Chae JS, Rahman MB, and Islam MA. A short history of Brucellosis: special emphasis in Bangladesh. Bangl J Vet Med. 2006; 4: 01-06.

DOI: $10.3329 /$ bjvm.v4i1.1517

4. Smits HL and Kadri S. M. Brucellosis in india: a deceptive infectious disease. Ind J Med Res. 2005; 122: $375-84$

5. Dean AS, CrumpL, Greter H, Hattendorf J, Schelling E, Zinsstag J. Clinical menifestations of human brucellosis: A systemic review and metaanalysis. PLOS Neg Trop Dis. 2012; 6: 1-8. DOI: 10.1371/journal.pntd.0001929

6. Mahdi NK, Abbas EM, and Aziz M AM. Occupational brucellosis among high risky human during their contacts with livestocks in basrah. MJBU. 2010; 28: 59-61.

7. Mukhtar F. Brucellosis in a high risk occupational group: seroprevalence and analysis of risk factors. J Pak Med Assoc. 2010; 60: 1031-4. ISSN: 0030-9982-L

8. Prakash P, Bhansali S, Gupta E, Kothari D, Mathur A, Ambuwani S. Epidemiology of Brucellosis in high risk group and PUO patients of Western - Rajasthan. N J Com Med. 2012; 3: 61-65. e-ISSN: 22296816

9. Pappas G, Papadimitriou P, A kritidis N, Christou L, Sianos EVT. The new global map of human brucellosis. Lancet Infect Dis. 2006; 6: 91-9. DOI:10.1016/S1473-3099(06)70382-6

10. Chowdhury OA, Ahmed F, Ahbab MA. Serosurvey of Brucella Antibody in Abattoir worker. Syl Med J. 2000; 21: 11-16.

11. Amin K MR, Rahman MB, Rahman MS, Han JC, Park JH, Chae IS. Prevalence of Brucella antibodies in sera of cows in Bangladesh. J Vet Sci. 2005; 6: 223-26.

DOI: $10.4142 /$ jvs.2005.6.3.223

12. Mantur BG and Amarnath SK. Brucellosis in India - a review. Bio sci. 2008; 33: 539-47.

13. Nahar A and Ahmed MU. Sero-prevalence study of Brucellosis in cattle \& contact human in Mymensingh district. Bangl J Vet Med. 2009; 7 : 269-74.

DOI: $10.3329 /$ bjvm.v7i1.5071

14. Rahman Md S, Sarker RR, Melzer F, Sprague LD, and Neubauer H. Brucellosis in human and domestic animals in Bangladesh: A review. Afr J microbiol Res. 2014; 8: 3580-94.

15. Rahman MS, Faruk MO, Her M, Kim JY, Kang SI, Jung SC. Prevalence of brucellosis in ruminant in Bangladesh. Vet Med. 2011; 8:379-85. DOI: 10.17221/1555-VETMED.

16. Araz GF and Azzam RA. Seroprevalence of brucella antibodies among persons in high risk occupation in Lebanon. Epidemiol Infect. 1996; 117: $281-88$

DOI: $10.1017 / 5095026880000145 \mathrm{X}$

17. Rahman AKM A, Dirk B, Fretin D, Saegerman C, Ahmed MU, Muhammad N, Hossain A, Abatih E. Seroprevalence and risk factors for Brucellosis in high risk group of individual in Bangladesh. Food Path Dis. 2012; 9: 190-97. DOI: $10.1089 /$ fpd.2011.1029

18. Sammartino LE, Gil A, Elzer P. Capacity building for surveillance and control of bovine and caprine brucellosis. Exp Consult Com Vet Pub H Sci. 2004; 3: 55-66.

19. Mukhtar F and Kokab F. Brucella serology in Abattoir workers. J Ayub Med Coll Abbottabad. 2008; 20: 57-61.

20. Muhammad N, Hossain MA, Musa AK,Mahmud MC, Paul SK, Rahman MA, Haque N, Islam MT, Parvin US, Khan SI, Nasreen SA, Mahmud NU. Seroprevalence of human brucellosis among the population at risk in rural area. Mymen Med J. 2010; 19:1-4.

21. Agasthya AS, Isloor S, Prabhudas K. Brucellosis in high risk group individuals. Indian J Med Microbiol. 2007;25:28-31. DOI: $10.4103 / 0255-0857.31058$

22. Aworh MK, Okolocha E, Kwaga J, Fasina F, Lazarus D, Suleman I, Poggensee G, Nguku p, Nsubuga p.Human brucellosis: seroprevalence and associated exposure factors among abattoir workers in Abuja, Nigeria-2011. Pan Afr Med J. 2013;16:103-08.

DOI: $10.11604 /$ pamj.2013.16.103.2143. 